\title{
Dietary polyphenol quercetin targets pancreatic cancer stem cells
}

\author{
WEI ZHOU ${ }^{1,5}$, GEORGIOS KALLIFATIDIS ${ }^{1,2}$, BERND BAUMANN ${ }^{3}$, VANESSA RAUSCH ${ }^{1,2}$, \\ JÜRGEN MATTERN ${ }^{1,2}$, JURY GLADKICH ${ }^{1,2}$, NATHALIA GIESE ${ }^{2}$, GERHARD MOLDENHAUER ${ }^{4}$, \\ THOMAS WIRTH ${ }^{3}$, MARKUS W. BÜCHLER ${ }^{2}$, ALEXEI V. SALNIKOV ${ }^{1,4}$ and INGRID HERR ${ }^{1,2}$ \\ ${ }^{1}$ Molecular OncoSurgery, University Hospital Heidelberg and German Cancer Research Center Heidelberg; \\ ${ }^{2}$ Department of General Surgery, University Hospital Heidelberg, Heidelberg; ${ }^{3}$ Institute of Physiological Chemistry, \\ University of Ulm, Ulm; ${ }^{4}$ Translational Immunology Unit, German Cancer Research Center, Heidelberg, Germany; \\ ${ }^{5}$ Department of Surgery, Sir Run Run Shaw Hospital, Zhejiang University, Hangzhou, P.R. China
}

Received May 3, 2010; Accepted June 17, 2010

DOI: 10.3892/ijo_00000704

\begin{abstract}
According to the cancer stem cell hypothesis the aggressive growth and early metastasis of pancreatic cancer may arise through dysregulation of self-renewal of stem cells in the tissue. Since recent data suggest targeting of cancer stem cells by some dietary agents we studied the effect of quercetin, a major polyphenol and flavonoid commonly detected in many fruits and vegetables. Using in vitro and in vivo models of pancreatic cancer stem cells we found quercetin-mediated reduction of self-renewal as measured by spheroid and colony formation. Quercetin diminished ALDH1 activity and reverted apoptosis resistance as detected by substrate assays, FACS and Western blot analysis. Importantly, combination of quercetin with sulforaphane, an isothiocyanate enriched in broccoli, had synergistic effects. Although quercetin led to enhanced binding of the survival factor $\mathrm{NF}-\mathrm{\kappa B}$, co-incubation with sulforaphane completely eliminated this pro-proliferative feature. Moreover, quercetin prevented expression of proteins involved in the epithelial-mesenchymal transition, which was even stronger in presence of sulforaphane, suggesting the blockade of signaling involved in early metastasis. In vivo, quercetin inhibited growth of cancer stem cell-enriched xenografts associated with reduced proliferation, angiogenesis, cancer stem cell-marker expression and induction of apoptosis. Co-incubation with sulforaphane increased these effects and no pronounced toxicity on normal cells or mice was observed. Our data suggest that food ingredients complement each other in the
\end{abstract}

Correspondence to: Professor Ingrid Herr, Experimental Surgery, University of Heidelberg, Im Neuenheimer Feld 365, 69120 Heidelberg, Germany

E-mail: i.herr@dkfz.de

Abbreviations: ALDH, aldehyde dehydrogenase; CSCs, cancer stem cells; EMT, epithelial-mesenchymal transition

Key words: cancer stem cells, chemopreventive agents, pancreatic cancer elimination of cancer stem cell-characteristics. Since carcinogenesis is a complex process, combination of bioactive dietary agents with complementary activities may be most effective.

\section{Introduction}

Over the last years increasing evidence points to the possibility that cancer may be based on a stem cell disease (1). Stem cells are long lived and capable of acquiring multiple mutations over time to transform to malignancy, while differentiated cells turn over rapidly (2). Like their normal counterparts, putative CSCs show remarkable resistance to radiation and chemotherapy (3). Clonal expansion of stem cell populations through dysregulated self-renewal is hypothesized to be an early step in carcinogenesis (4). Thus, putative cancer stem cells (CSCs) have been made responsible for tumor initiation, growth, metastasis and relapse after treatment.

Markers for CSCs have been identified in different tumor entities including pancreatic cancer and the presence correlates to the extreme aggressiveness of this tumor $(5,6)$. In half of patients with pancreatic adenocarcinoma metastasis is detectable already at the time of diagnosis. Only in $20 \%$ of patients surgical resection is possible and the prognosis is poor. The high resistance of pancreatic cancer to conventional cytotoxic therapy highlights the important need to develop more effective non-toxic strategies. If the CSC hypothesis is valid, then strategies aimed at targeting stem cell self-renewal pathways represent rational approaches for cancer prevention and treatment.

$\mathrm{NF}-\kappa \mathrm{B}$ signaling is activated in pancreatic cancer and thought to promote tumorigenesis, mainly through its ability to protect transformed cells from apoptosis $(7,8)$. NF-кB is required for the induction of epithelial-mesenchymal transition (EMT), which is associated with early steps of metastasis. Also, an essential role for $\mathrm{NF}-\kappa \mathrm{B}$ in late-stage tumorigenesis has been suggested (9). There is evidence that the isothiocyanate sulforaphane, present in high concentration in broccoli, is anti-inflammatory and inhibits NF- $\mathrm{BB}$ binding to DNA as demonstrated in mouse macrophages (10). Accordingly, we recently showed that sulforaphane inhibits $\mathrm{NF}-\kappa \mathrm{B}$ activity in a model of established pancreatic CSCs, thereby sensitizing 
them to apoptosis induction (11). Other dietary agents and potent NF-кB inhibitors, are the polyphenols such as curcumin (12), found in spices, or piperine (13), isolated from black and long peppers. These plant substances have recently been demonstrated to inhibit self-renewal of breast CSCs (14). Most importantly, quantitative combination effects between e.g., curcumin and piperine, and sulforaphane and 3,3-diindolylmethane, another broccoli ingredient, were observed $(14,15)$.

The effects of quercetin, a major polyphenol and flavonoid present in nearly all plants, in self-renewal and therapy resistance of pancreatic CSCs have not yet been explored. Quercetin is commonly detected in apples, cranberries, blueberries and onions. Many biological and pharmacological activities that may be beneficial to human health have been attributed to quercetin, including antioxidant, anticarcinogenic, anti-inflammatory, and cardioprotective activities (16). Here we demonstrate that quercetin potently eliminates pancreatic CSC characteristics by affecting clonogenicity, spheroid formation, ALDH1 activity along with signaling involved in apoptosis resistance, proliferation, angiogenesis, NF-кB and EMT. We demonstrate that sulforaphane is able to increase these effects in vitro and in vivo without inducing toxic side-effects. These studies stress the need for elucidating combination of dietary intervention with conventional cytotoxic therapy for more successful elimination of highly therapy resistant CSCs.

\section{Materials and methods}

Human primary and established cell lines. BxPc-3 and MIA-PaCa2 pancreatic cancer cell lines were obtained from the American Type Culture Collection (Manassas, VA, USA). Human non-malignant primary skin fibroblasts were kindly provided by Dr H.-J. Stark (DKFZ, Heidelberg, Germany). Cells were cultured in DMEM (PAA Laboratories, Pasching, Austria) supplemented with 10\% FBS (SigmaAldrich, St. Louis, MO, USA) and $10 \mathrm{mM}$ HEPES (PAA Laboratories). Mesenchymal stromal/stem cells were isolated from bone marrow and cultured as described (17).

Reagents. Quercetin 95\% pure (Cayman, Ann Arbor, MI, USA) and Z-VAD-FMK (Promega, Madison, WI, USA) were prepared in dimethyl sulfoxide (DMSO, AppliChem GmbH, Darmstadt, Germany). Sulforaphane 95\% pure (Sigma-Aldrich, Deisenhofen, Germany) was prepared in $99 \%$ ethanol. Final concentrations of the solvents in medium were $\leq 0.1 \%$.

Nude mice and xenografts. MIA-PaCa2 cells $\left(4 \times 10^{6}\right.$ in $200 \mu 1$ of PBS) were injected subcutaneously into the right anterior flank of 4-6 weeks old NMRI (nu/nu) male mice (day 0). After the MIA-PaCa2 tumors had reached a mean diameter of about 8-10 mm, mice were randomly divided into four groups of six animals each and treatment was initiated. The mice were treated intraperitoneally with i) sulforaphane at a dose of $4.4 \mathrm{mg} / \mathrm{kg}$, ii) quercetin at a dose of $50 \mathrm{mg} / \mathrm{kg}$, iii) a combination of sulforaphane and quercetin at aforementioned dose, or iv) PBS vehicle on day 5, 6, and 7 after tumor cell implantation. Tumor growth was monitored daily by measuring two diameters with calipers and tumor volumes v) were calculated using the formula $\mathrm{V}=1 / 2$ (length $\mathrm{x}$ width ${ }^{2}$ ). Mice were euthanized at day 10. Animal experiments were carried out in the animal facilities of the DKFZ after approval by the authorities (Regierungspräsidium Karlsruhe, Germany).

Measurement of apoptosis. Cells were stained with fluoresceinisothiocyanate (FITC)-conjugated annexin V (Invitrogen, Camarillo, CA, USA) after respective treatment. Externalization of phosphatidylserine was identified by flow cytometry (FACScan, BD Biosciences, Heidelberg, Germany) (11).

MTT-assay. Cells were resuspended at a density of $5 \times 10^{4}$ $1.5 \times 10^{5}$ cells per $\mathrm{ml}$ in 96 -well plates, $100 \mu 1$ per well. After treatment, the MTT-assay was performed as described (11).

Spheroid assay. Cells were cultured in NeuroCult ${ }^{\circledR}$ NS-A basal serum-free medium (Stem Cell Technologies Inc., Vancouver, BC, Canada) supplemented with $2 \mu \mathrm{g} / \mathrm{ml}$ Heparin (Stem Cell Technologies Inc.), $20 \mathrm{ng} / \mathrm{ml}$ hEGF (R\&D Systems, Wiesbaden-Nordenstadt, Germany), $10 \mathrm{ng} / \mathrm{ml}$ hFGF-b (PeproTech GmbH, Hamburg, Germany) and NeuroCult NS-A human proliferation supplements (Stem Cell Technologies Inc.) as described (11).

Colony formation assays. Tumor cells were seeded at a density of $1 \times 10^{5}$ cells per well in 6-well tissue culture plates (BD Falcon $^{\mathrm{TM}}$, San José, CA, USA) and colony formation was evaluated as described (11).

Detection of ALDH1 activity. Aldefluor substrate $(2.5 \mu 1$, Aldagen, Inc., Durham, NC, USA) was added to $1 \times 10^{6}$ tumor cells in $500 \mu \mathrm{l} / \mathrm{ml}$ assay buffer and incubated for $60 \mathrm{~min}$ at $37^{\circ} \mathrm{C}$. Cells were analyzed by flow cytometry according to the instructions of the manufacturer. Treatment of cells with $5 \mu 1$ of the ALDH1 inhibitor diethylamino-benzaldehyde (DEAB) served as negative control.

Detection of caspase activity. A kit providing fluorochrome inhibitor of caspases (FLICA) was used according to the manufacturer's protocol (Immunochemistry Technologies, Bloomington, MN, USA). In short, FLICA solution specific for caspases 3 and 7, 8 or 9 was added to the cell culture medium and incubated for $1 \mathrm{~h}$ at $37^{\circ} \mathrm{C}$ in $5 \% \mathrm{CO}_{2}$. Cells were then analyzed by flow cytometry or immunofluorescence microscopy.

Protein isolation and Western blot analysis. Whole cell extracts were prepared by a standard protocol as described (11) and proteins were detected by Western blot analysis using rabbit polyclonal Abs anti-PARP p85 fragment (Promega), E-cadherin (Cell Signaling Technology, Danvers, MA, USA), and mouse mAbs Twist 2 and vimentin (Abcam, Cambridge, UK).

Immunohistochemistry and immunofluorescence analysis of xenograft tissue. Immunohistochemistry on $6 \mu \mathrm{m}$ frozen xenograft sections was performed as described previously (11). Abs used were rat anti-mouse CD31 mAb (PharMingen, San Diego, CA), rabbit polyclonal Ab towards cleaved fragment of activated human caspase 3 (R\&D Systems) or human Ki-67 (Thermo Scientific, Rockford, IL, USA), and mouse mAb from SWA-11 hybridoma for detection of CD24. 
<smiles>O=c1c(O)c(-c2ccc(O)c(O)c2)oc2cc(O)cc(O)c12</smiles>

\section{Sulforaphane (SF)}<smiles>CS(=O)CCCCN=C=S</smiles>

B
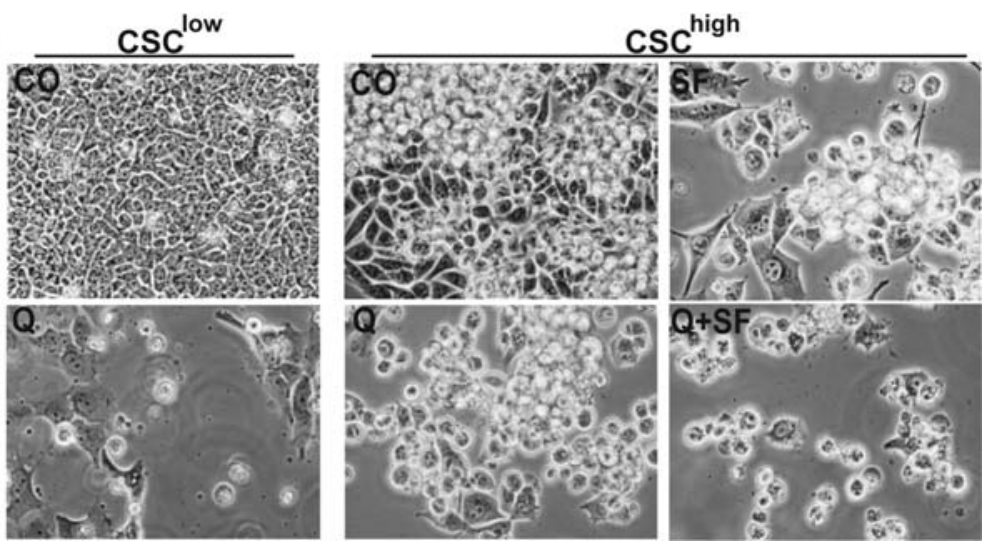

Figure 1. Quercetin is toxic for CSC-like cells and sulforaphane increases the effect. (A) Chemical formulas of the polyphenol quercetin and the isothiocyanate sulforaphane are shown. (B) $\mathrm{CSC}^{\text {low }}(\mathrm{BxPc}-3)$ or $\mathrm{CSC}^{\text {high }}$ (MIA-PaCa2) cells were left untreated (CO) or were treated with quercetin (200 $\left.\mu \mathrm{M}\right)$, sulforaphane $(10 \mu \mathrm{M})$, or both together $(\mathrm{Q}+\mathrm{SF})$ as indicated. Representative images of morphological changes $48 \mathrm{~h}$ after treatment are shown under magnification $\mathrm{x} 100$.

Table I. CSC characteristics of CSC ${ }^{\text {high }}$ MIA-PaCa2 and CSC ${ }^{\text {low }}$ BxPc-3 cells.

\begin{tabular}{lllc}
\hline & \multicolumn{1}{c}{ MIA-PaCa2 } & \multicolumn{1}{c}{ BxPc-3 } & (Refs.) \\
\hline ATCC no. & CRL-1420 & CRL-1687 & ATCC \\
Source & Primary tumor & Biopsy primary tumor & ATCC \\
Degree of tumor differentiation & Poor & Well & ATCC \\
Therapy resistance & High & Low & $(11)$ \\
Colony-forming capacity & High & None & $(11)$ \\
Spheroid-forming capacity & $82 \%$ & None & Present study \\
Secondary spheroid formation & High & No & $(11)$ \\
ALDH activity & Yes & Yes, very slow & $(11)$ \\
Growth on nude mice & Yes, very fast & Yes, but not consistent & $(11)$ \\
Serial transplantation in vivo & Yes, very fast & $17.5 \pm 5.7$ & $(11)$ \\
CD44+CD24- & $95.5 \pm 3.7$ & No & $(11)$ \\
CD133 & Yes, upon hypoxia & No & Data not shown \\
Differentiation potential & Yes & High & Present study \\
E-cadherin expression & Lost & Present study \\
\hline
\end{tabular}

Electrophoretic mobility shift assay (EMSA). Whole cell extract was harvested and EMSA was performed as recently described (11).

Statistical evaluations. For MTT and FACS measurements statistical evaluations are presented as the mean \pm SD. Data were analyzed using the Student's t-test. $\mathrm{p}<0.05$ was considered statistically significant. For xenografts on nude mice a distribution free test for tumor growth curve analyses for therapy experiments with xenografted cancer cells was used as described by Koziol et al (18).

\section{Results}

Quercetin is cytotoxic to CSCs and sulforaphane increases the effect. To evaluate the effect of the polyphenol quercetin alone and in combination with the isothiocyanate sulforaphane (Fig. 1A) in pancreatic CSCs we used the human established pancreatic cancer cell lines MIA-PaCa2 and BxPc-3. These cell lines have been characterized in our recent study as $\mathrm{CSC}^{\text {high }}$ and $\mathrm{CSC}^{\text {low }}$ cells (Table I). Morphologically, $\mathrm{CSC}^{\text {low }}$ cells consist of one adherent phenotype, whereas $\mathrm{CSC}^{\text {high }}$ cells contain spheroidal floating cells and adherent cells suggesting 

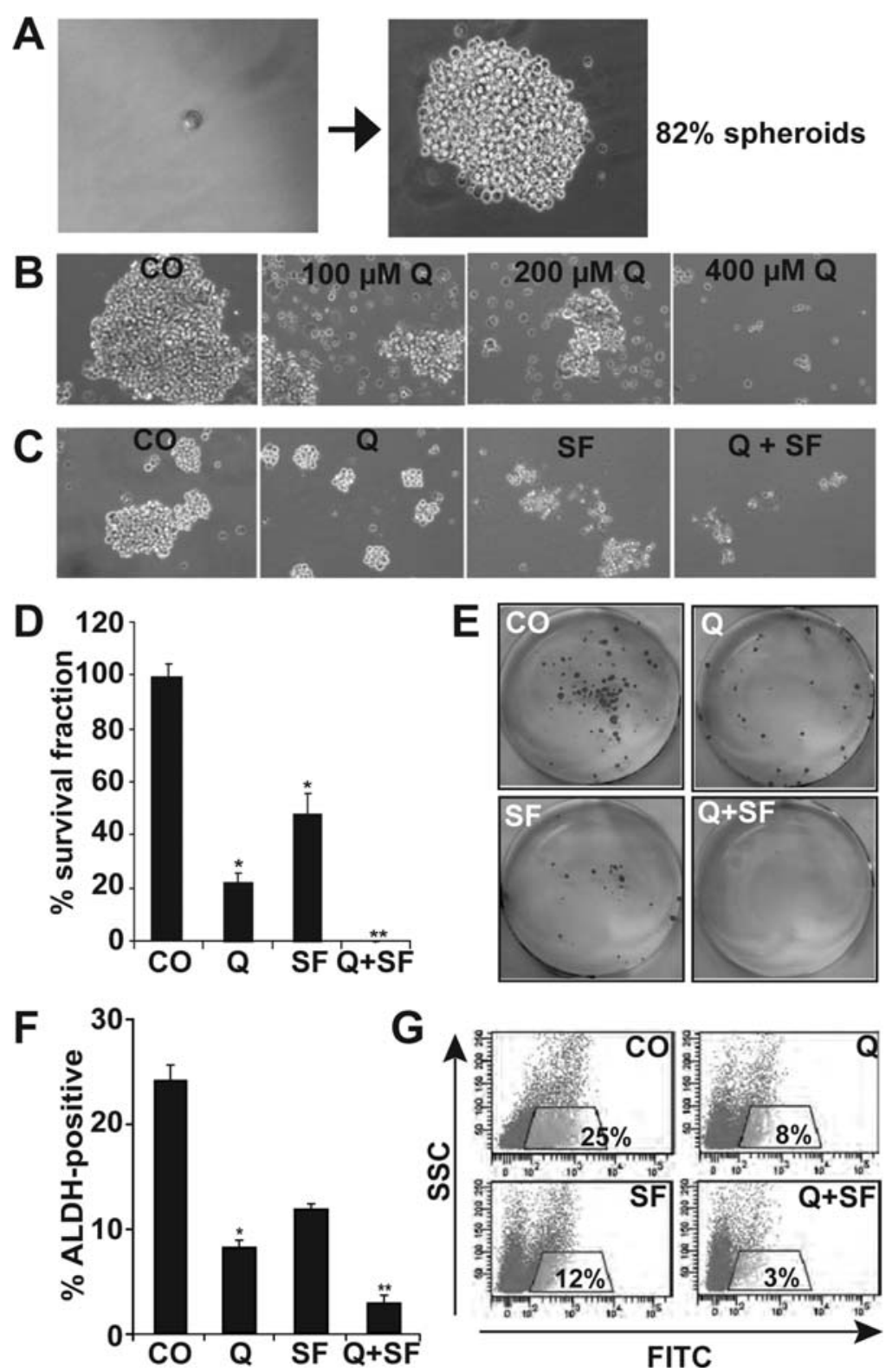

Figure 2. Quercetin inhibits self-renewal and ALDH1 activity of CSC-like cells and sulforaphane increases the effect. (A) The percentage of spheroid-forming $\mathrm{CSC}^{\text {high }}$ cells was evaluated by seeding 1 cell per well in NS-A medium. Ten days later, spheroid formation in wells was evaluated showing that $82 \%$ of single cells formed spheroids. Representative image of a single cells at the beginning of the experiment and of a spheroid 10 days after incubation. (B) Spheroids nine days after treatment of $\mathrm{CSC}^{\text {high }}$ cells with 100,200 or $400 \mu \mathrm{M}$ quercetin or (C) seven days after treatment with quercetin $(200 \mu \mathrm{M})$, SF $(10 \mu \mathrm{M})$, or both together $(\mathrm{Q}+\mathrm{SF})$ at the aforementioned doses were evaluated under magnification $\mathrm{x} 100$. (D) CSC high cells were seeded in 6-well tissue culture plates and treated as indicated. Seventy-two hours later, cells were trypsinized and re-plated in 6-well plates. Ten days later colonies containing >50 cells were counted under a dissecting Zeiss Stemi DV4 microscope. The number of colonies in the control group was set to $100 \%$ and the percentage of survival fraction in the treatment groups was calculated $\left({ }^{*} \mathrm{p}<0.05\right.$ compared with control; ${ }^{* *} \mathrm{p}<0.01$ compared with control). (E) Photographs of the fixed and coomassie-stained colonies are presented on the right. (F) Seventy-two hours after treatment ALDH1 activity was analyzed by flow cytometry and the percentage of ALDH-positive cells is presented on the left $\left(* \mathrm{p}<0.05\right.$ compared with control; ${ }^{* *} \mathrm{p}<0.01$ compared with control). (F) Representative blots of the FACS measurements are presented on the right.

differentiation potential (Fig. 1B). Quercetin was used in a concentration of $200 \mu \mathrm{M}$ according to a recent publication in which similar concentrations of quercetin induced efficient apoptosis of pancreatic cancer cells (19). In the present study, most of CSC $^{\text {low }}$ tumor cells were eliminated by $200 \mu \mathrm{M}$ quercetin within $48 \mathrm{~h}$, while the majority of spheroidal growing $\mathrm{CSC}^{\text {high }}$ cells survived. Since concentrations higher than $200 \mu \mathrm{M}$ of quercetin are unrealistic in the clinical setting, where peak plasma concentrations of $108.7 \pm 41.67 \mu \mathrm{M}$ quercetin have been observed (20), and flavonoids naturally act in concert with other plant ingredients, we evaluated a putative synergistic effect of sulforaphane. Sulforaphane was used at a concentration of $10 \mu \mathrm{M}$, since we already demonstrated that this dose effectively sensitizes pancreatic CSCs to apoptosis without inducing any cytotoxic side-effects to normal cells (11). While quercetin and sulforaphane alone strongly induced cell death in $\mathrm{CSC}^{\text {high }}$ cells, the combination increased the appearance of an apoptotic phenotype.

Quercetin targets CSC characteristics and sulforaphane increases the effect. To examine the impact of quercetin on self-renewal of CSCs, we performed spheroid- and colony- 
forming assays. We tested CSC high cells but not $\mathrm{CSC}^{\text {low }}$ cells, since the latter ones do not form spheroids and colonies (Table I). CSC ${ }^{\text {high }}$ cells were seeded in 96-well plates in NS-A medium, 1 cell per well. Wells with $>1$ cell were excluded from the experiment. Ten days later, cells were evaluated for spheroid formation. Fourteen of 17 evaluated single cells $(82 \%)$ had formed spheroids, demonstrating the selfrenewal potential of this cell line (Fig. 2A). Treatment with quercetin starting with $100-400 \mu \mathrm{M}$ resulted in a dosedependent destruction of spheroids within 9 days, which was blocked completely with the highest concentration (Fig. 2B). Similar results were obtained upon treatment with $10 \mu \mathrm{M}$ sulforaphane, which strongly diminished but did not totally eradicate spheroids (Fig. 2C). Double treatment with $200 \mu \mathrm{M}$ quercetin and $10 \mu \mathrm{M}$ sulforaphane was much more effective than each single treatment alone and totally abolished spheroid formation. Since co-incubation of $200 \mu \mathrm{M}$ quercetin and $10 \mu \mathrm{M}$ sulforaphane was effective, we used these concentrations for all following experiments. For further evaluation of the influence of quercetin to self-renewal we performed colony formation assays. Single treatment with quercetin or sulforaphane inhibited colonies to 25 and $45 \%$, respectively, while combined treatment completely abolished them (Fig. 2D and E). ALDH1 activity, another suggested feature of CSCs (21), decreased upon incubation with the single agents and combination led to an additive reduction (Fig. 2F and G). These data indicate that quercetin is suitable for targeting of pancreatic CSCs, while combination with sulforaphane strongly enhances the effect.

Quercetin overcomes apoptosis resistance of CSCs and sulforaphane increases the effect. To investigate whether quercetin might overcome apoptosis resistance of CSCs, we used annexin $\mathrm{V}$ staining for detection of phosphatidylserine exposure, which is an early step of programmed cell death. As expected, quercetin induced strong apoptosis in sensitive $\mathrm{CSC}^{\text {low }}$ cells up to $43 \%$ after $72 \mathrm{~h}$ (Fig. $3 \mathrm{~A}$, left panel). In contrast, quercetin induced $<10 \%$ apoptosis and sulforaphane $15 \%$ apoptosis in resistant $\mathrm{CSC}^{\text {high }}$ cells (Fig. 3A, right panel). However, combination of both substances increased the apoptosis rate to $42 \%$. Corresponding to inhibition of apoptosis, we found cell cycle arrest in the G2/M phase in a dosedependent manner by treatment of $\mathrm{CSC}^{\text {high }}$ cells with quercetin (data not shown). To investigate the potential mechanisms of quercetin- and sulforaphane-induced apoptosis, we analyzed initiator caspases 8 and 9, executor caspases 3 and 7, and the cleavage of the caspase substrate poly (ADP-ribose) polymerase (PARP). In $\mathrm{CSC}^{\text {low }}$ cells, single treatment with quercetin significantly induced activation of caspases (Fig. 3B) and cleavage of PARP (Fig. 3C) within $48 \mathrm{~h}$, but was less effective in $\mathrm{CSC}^{\text {high }}$ cells. However, combination of both dietary ingredients led to increased caspase activation and PARP cleavage. Additionally, apoptosis induced by single or combination treatment was caspase-dependent, since preincubation of cells with the pan-caspase inhibitor Z-VAD-FMK significantly decreased apoptosis in $\mathrm{CSC}^{\text {low }}$ and - to a somehow lesser extent - also in CSC ${ }^{\text {high }}$ cells (Fig. 3D). These data suggest that apoptosis induced by quercetin and sulforaphane is caspase-dependent and involves cleavage of PARP. However, $\mathrm{Z}-\mathrm{VAD}-\mathrm{FMK}$ was less effective in $\mathrm{CSC}^{\text {high }}$ cells, suggesting that apoptosis is not the only mechanism by which quercetin and sulforaphane mediate sensitization of $\mathrm{CSC}^{\text {high }}$ cells to apoptosis. Most importantly, dietary agents alone or combined did not exhibit pronounced toxicity to normal cells as examined by MTT analysis of human primary skin fibroblasts and mesenchymal stromal/stem cells (data not shown).

Quercetin affects signaling involved in proliferation and early metastasis and sulforaphane completes this effect. Since NF-кB is a prominent factor in controlling tumor growth and apoptosis resistance of pancreatic CSCs (11), we evaluated DNA-binding of NF-кB before and after treatment of $\mathrm{CSC}^{\text {high }}$ and $\mathrm{CSC}^{\text {low }}$ cells with quercetin, sulforaphane or both together (Fig. 4A). Quercetin induced strong binding of NF- $\mathrm{KB}$, which was unexpected, since this may be associated with EMT and cancer progression. However, while sulforaphane itself did not enhance $\mathrm{NF}-\mathrm{\kappa B}$ binding, it mediated a marked reduction of quercetin-induced NF-кB binding in $\mathrm{CSC}^{\text {low }}$ cells and totally abolished it in $\mathrm{CSC}^{\text {high }}$ cells. To further characterize the composition of the quercetin-induced NF- $\mathrm{KB}$ complexes we performed supershift assays with specific antibodies recognizing the various NF-кB subunits. The use of p65/RelA-, p50 (p50up)- and cRel-specific antibodies resulted in supershifts while RelB- and p52-specific shifts could not be detected. Only in the presence of the p50-specific antibody a complete shift of the quercetin-induced DNA-binding activity occurred. These results indicate that most probably p50/p65 and to lesser extent $\mathrm{p} 50 / \mathrm{c}-\mathrm{Rel}$ heterodimers are responsible for quercetinmediated NF-кB activity, which is totally prevented by coincubation with sulforaphane.

Due to a recent report suggesting the generation of breast CSCs by Twist (22), a protein involved in EMT, we assessed expression of Twist 2 and EMT-related proteins E-cadherin and vimentin by Western blot analysis. E-cadherin was highly expressed in $\mathrm{CSC}^{\text {low }}$, but not detectable in $\mathrm{CSC}^{\text {high }}$ cells. Downregulation of E-cadherin characterizes that cells lose contact during EMT, which corresponds to the spheroidal phenotype of $\mathrm{CSC}^{\text {high }}$ cells (Fig. 4B). Accordingly, the mesenchymal markers vimentin and Twist 2 were only expressed in $\mathrm{CSC}^{\text {high }}$ cells, which is in line with the suggested upregulation of these proteins during EMT (23). Quercetin did not alter E-cadherin expression in either cell line. However, quercetin diminished vimentin and Twist 2 expression in CSC ${ }^{\text {high }}$ cells 4 and $24 \mathrm{~h}$ after treatment, suggesting inhibition of EMT. Although sulforaphane alone had no effect, combination with quercetin further diminished vimentin expression at $4 \mathrm{~h}$ and Twist 2 expression $24 \mathrm{~h}$ after incubation. Together, these results indicate quercetin-induced survival signaling is totally abrogated by combination with sulforaphane. Also, inhibition of EMT by quercetin is enhanced upon combination with sulforaphane, suggesting inhibition of early metastasis signaling.

Quercetin diminishes growth of CSC-xenografts, which is completed by sulforaphane. To evaluate the in vivo therapeutic function of quercetin, $\mathrm{CSC}^{\text {high }}$ cells were xenografted subcutaneously to nude mice. A dose of $50 \mathrm{mg} / \mathrm{kg}$ quercetin was chosen related to a recent publication showing quercetinmediated inhibition of pancreatic cancer xenografts (19). Sulforaphane was used at $4.4 \mathrm{mg} / \mathrm{kg}$, since this concentration 
A

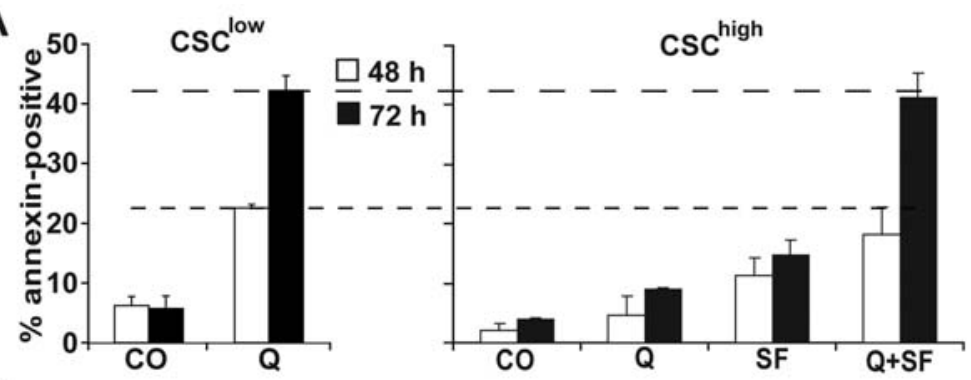

B

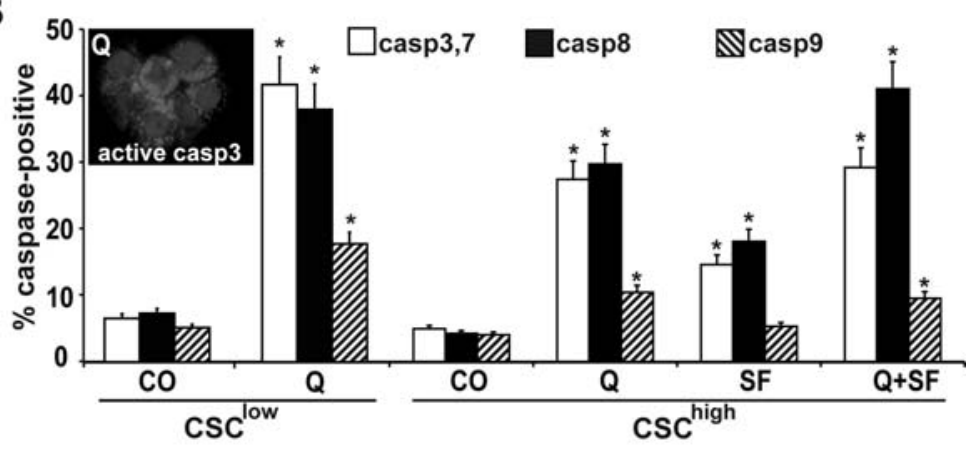

C

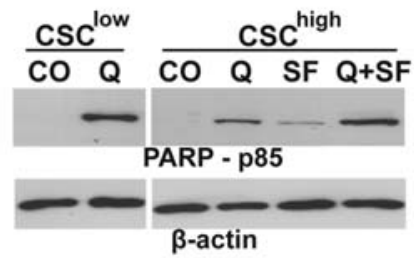

D
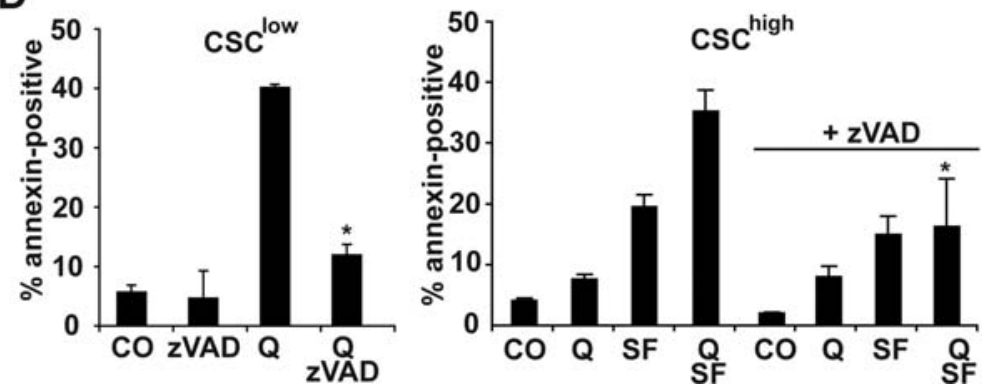

Figure 3. Quercetin overcomes apoptosis resistance of CSC-like cells and sulforaphane increases the effect. (A) Apoptosis was measured by annexin V staining and flow cytometry 48 or $72 \mathrm{~h}$ after treatment with quercetin $(200 \mu \mathrm{M})$, sulforaphane $(10 \mu \mathrm{M})$, or both together $(\mathrm{Q}+\mathrm{SF})$ at the aforementioned doses. (B) Forty-eight hours after treatment as described above, activity of caspases 3 and 7, 8, and 9 was measured by FLICA staining and analyzed by flow cytometry and the percentage of caspase-positive cells is shown. One representative immunofluorescence microscopy picture of quercetin-induced active caspase 3 and 7 in $\mathrm{CSC}^{\text {low }}$ cells is presented. ${ }^{*} \mathrm{p}<0.05$ compared with control. (C) Twenty-four hours after treatment as described above, expression of the p85 fragment of PARP was analyzed by Western blotting. Expression of $\beta$-actin served as loading control. (D) CSC ${ }^{\text {low }}$ and CSC $^{\text {high }}$ cells were pre-incubated with the broad spectrum caspase inhibitor Z-VAD-FMK for $2 \mathrm{~h}$ and then exposed to quercetin, sulforaphane or both together (Q+SF) for $72 \mathrm{~h}$ at doses indicted above. Apoptosis induction was evaluated by annexin V staining and flow cytometry and is presented as percentage of annexin-positive cells. ( ${ }^{*} \mathrm{p}<0.05$ compared with cells without Z-VAD-FMK pre-incubation).

strongly reduced growth of pancreatic CSC-xenografts without toxic side-effects in our recent data (11). In the present study daily administration of quercetin for three consecutive days strongly reduced rapid growth of CSC-xenografts (Fig. 5A). Sulforaphane had similar effects, but combination completely abrogated tumor growth. Importantly, neither changes in body weight nor necrotic area in mouse liver tissues were detected (Fig. 5B) suggesting that combination treatment with quercetin and sulforaphane is well tolerated by the mice.

To investigate the potential mechanisms of xenograft tumor growth retardation, tumor tissue samples were analyzed. As measured by Ki-67 staining, proliferation was reduced by single treatment, which was significantly diminished upon combination (Fig. 5C and D). Similarly, apoptosis was induced by both treatments as illustrated by staining of the cleaved fragment of active caspase 3. However, combination did not further increase the number of active caspase 3-positive cells, which is in line with our in vitro data (see Fig. 3B). To detect any influence on angiogenesis, which may be important for prevention of metastasis, we stained endothelial cells with the specific marker CD31. We found a slight but significant decrease in the density of CD31-positive endothelial cells of blood vessels in xenografts treated with quercetin alone compared to untreated controls. Combined treatment did not 


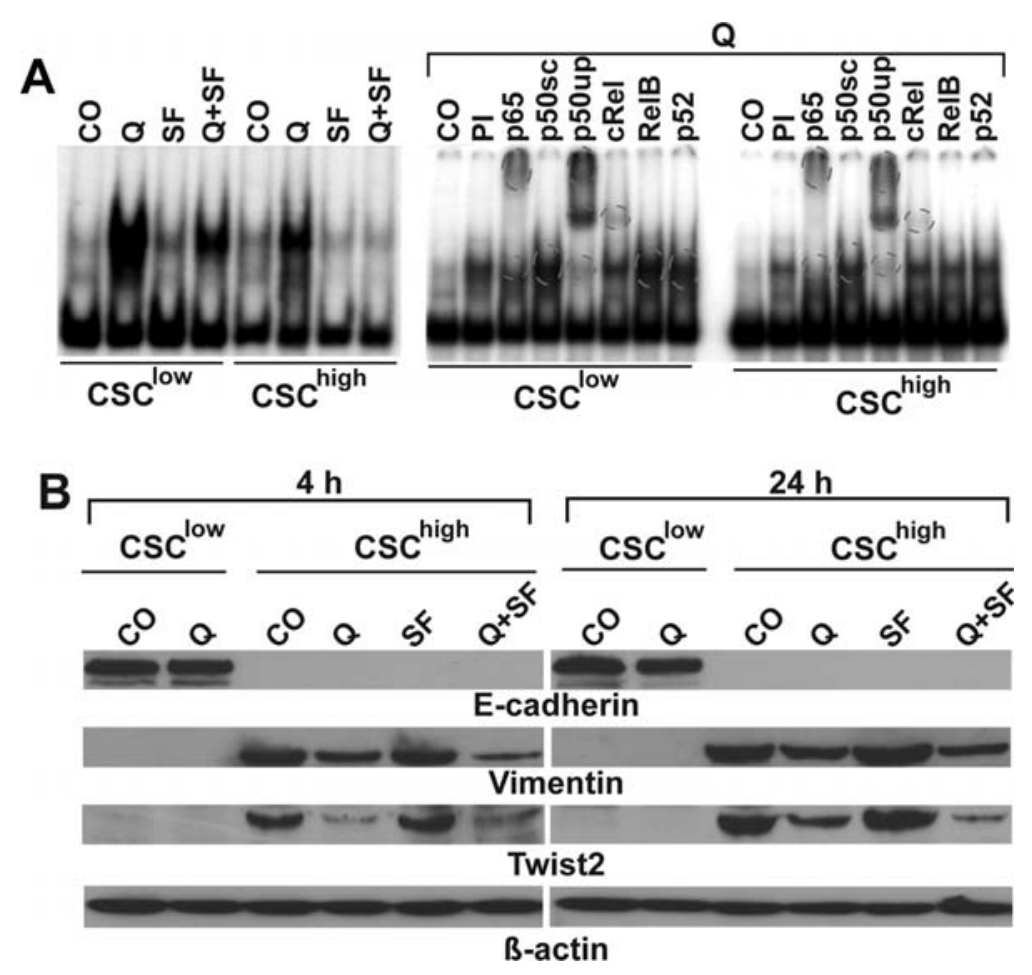

Figure 4. Quercetin affects proliferation and pre-metastatic signaling and sulforaphane completes this effect. (A) Whole cell extracts were prepared $24 \mathrm{~h}$ posttreatment as indicated and described above and DNA binding was analyzed by EMSA using a specific ${ }^{32}$ P-labeled oligonucleotide probe for NF- $\mathrm{KB}$ (right). Nuclear proteins derived from cells treated with quercetin $(\mathrm{Q})$ for $24 \mathrm{~h}$ were pre-incubated for $30 \mathrm{~min}$ with specific antibodies followed by EMSA analysis (left). In case of p50 two different Abs for the same protein were used: p50sc and p50up. Broken circles mark disappearance of shifted complexes or enhanced shifts due to specific interaction with co-incubated Abs. (B) Four and $24 \mathrm{~h}$ after treatment EMT proteins E-cadherin, vimentin, and Twist2 were analyzed by Western blotting using whole cell extracts. Expression of $\beta$-actin served as internal loading control.

further decrease the number of CD31-positive vessels. Finally, we analyzed the presence of an $\mathrm{CD} 44^{+} / \mathrm{CD} 24-$ phenotype, which has been recently characterized as CSC marker in the MIA-PaCa2 CSC ${ }^{\text {high }}$ cell line (11). While we found CD44+ single and $\mathrm{CD} 44^{+} / \mathrm{CD} 24^{+}$double-positive cells already in untreated cells, no change in the percentage of expression could be detected after treatment (data not shown). However, we detected an increase in the percentage of $\mathrm{CD} 24^{+}$singlepositive cells after combination treatment (Fig. 5C and D). This finding suggests clearance of CD24- CSCs by treatment resulting in an enrichment of $\mathrm{CD} 24^{+}$non-CSCs. We conclude from these data that the major mechanism of CSC elimination and tumor growth retardation after quercetin and sulforaphane treatment of mice is an anti-proliferative and pro-apoptotic effect.

\section{Discussion}

We show that the phytochemical quercetin downregulates CSC characteristics using an established model of pancreatic cell lines enriched in CSC markers. Co-incubation with the phytochemical sulforaphane increases the observed effects and re-sensitized the highly resistant cells to apoptosis. Importantly, no toxicity in cultured primary cells and in mice was observed suggesting that dietary supplements containing high concentrations of quercetin and sulforaphane may be well tolerated by patients.

The CSC characteristics of the model cell lines CSChigh MIA-PaCa2 and CSC ${ }^{\text {low }} \mathrm{BxPc}-3$ cells used in the present study have been described already in part in our recent study (11). The CSC phenotype is characterized by a CD $44^{+} / \mathrm{CD} 24$ population with high capacity to form colonies and spheroids, ALDH1 activity, high apoptosis resistance and the ability to form tumors in nude mice. In the present study we identified that $82 \%$ of MIA-PaCa2 cells have spheroid-forming capacity. Also, the present study describes for the first time the presence of two cell populations in MIA-PaCa2 cells, namely spheroidal cells and fibroblast-like adherent cells, which may indicate differentiation potential of CSCs. The spheroidal growing cell population in MIA-PaCa2 cells may correspond to more primitive stem cells and loss of E-cadherin expression, as demonstrated in our Western blot analysis, may have contributed to the minor adherent and highly resistant phenotype. This suggestion is underscored by findings of Lowy et al (24), who demonstrated that E-cadherin expression is necessary for cell adhesion in pancreatic cancer cells. Thus, loss of E-cadherin may provide pancreatic cancer cells with a growth advantage that contributes to tumor progression.

In the present study, treatment of $\mathrm{CSC}^{\text {low }}$ cells with quercetin resulted in a pronounced activation of caspases, PARP cleavage, and externalization of phosphatidylserine, suggesting activation of a classical caspase-dependent apoptotic pathway. $\mathrm{CSC}^{\text {high }}$ cells were more resistant to apoptosis induction by quercetin, but combination with sulforaphane completely restored sensitivity. Since inhbition of caspase activity did not completely rescue $\mathrm{CSC}^{\text {high }}$ cells from apoptosis, we assume that both caspase-dependent and caspase-independent mechanisms are involved in the observed complete elimination of CSCs by 

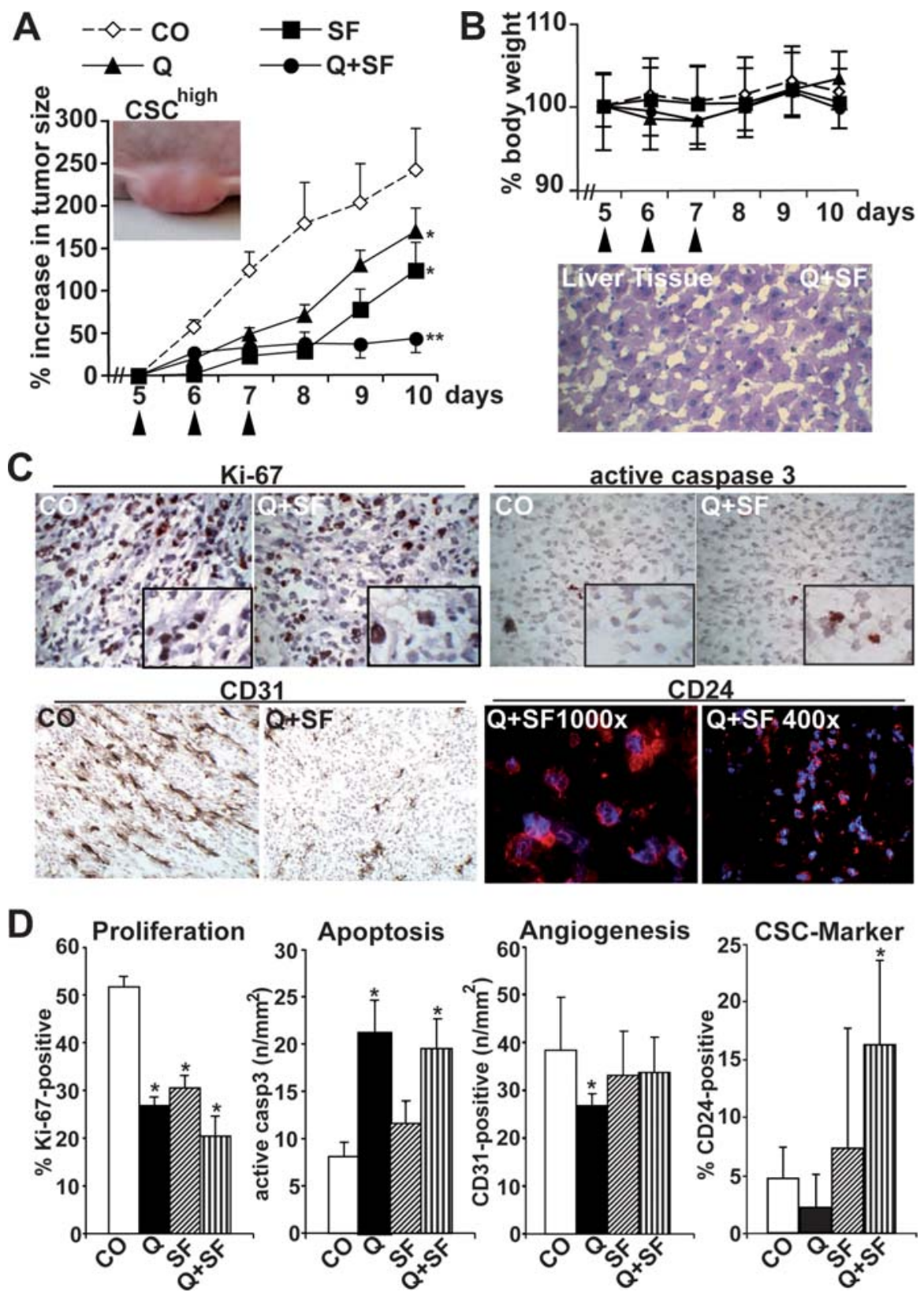

Figure 5. Quercetin inhibits growth of CSC-enriched xenografts in vivo and sulforaphane strongly increases this effect. (A) CSChigh cells (4x10 6 cells in $200 \mu 1$ of PBS) were injected subcutaneously into nude mice. After the tumors had reached a mean diameter of 8-10 mm, quercetin, sulforaphane or both agents together $(\mathrm{Q}+\mathrm{SF})$ were administered at days 5,6 and 7 after tumor cell implantation. The tumor volume was measured daily. Mice were euthanized on day 10 . Data are presented as mean of 6 animals $\pm \mathrm{SD}\left({ }^{*} \mathrm{p}<0.05\right.$ compared with control; ${ }^{* *} \mathrm{p}<0.01$ compared with control). (B) Body weight of each individual mouse was set to $100 \%$ before treatment. Mice were weighed daily and relative changes in body weight are shown. A representative H\&E staining of liver tissue at day 13 after tumor cell implantation from mice treated with quercetin and sulforaphane is shown. (C) CSChigh tumors were collected at day 13 after tumor cell implantation. Frozen tumor tissue sections were subjected to immunohistochemistry for Ki-67, active caspase-3, CD31 and CD24/DAPI. (D) Proliferation was analyzed by counting Ki-67-positive cells in 10 vision fields. Proliferation index and the percentage of CD24 single positive cells were calculated as a percentage of positive tumor cells from total tumor cell mass. Apoptosis was evaluated based on the density of active caspase 3-positive cells and angiogenesis a as the number of CD31-positive vessels per $\mathrm{mm}^{2}$ of tumor tissue.

co-treatment. Such caspase-independent cell death of CSC ${ }^{\text {high }}$ cells may include inhibition of pathways necessary for proliferation and self-renewal capacity. Indeed, involvement of such pathways was confirmed in the present study by spheroidand colony-forming capacity, which was inhibited by quercetin alone and much more pronounced upon combination with sulforaphane.

In addition to disturbed self-renewal and apoptosis resistance in $\mathrm{CSC}^{\text {high }}$ cells, constitutive $\mathrm{NF}-\kappa \mathrm{B}$ activation may contribute to the resistant CSC phenotype. Involvement of
$\mathrm{NF}-\kappa \mathrm{B}$ in aggressive growth and metastatic potential has been observed in many malignant tumors including pancreatic CSCs $(11,25)$. Thus, inhibition of NF- $\kappa \mathrm{B}$ is a well-known mechanism to sensitize resistant cancer cells to therapy. Hence, we recently demonstrated that sulforaphane totally abrogates TRAIL-induced NF- $\kappa \mathrm{B}$ activity and sensitizes $\mathrm{CSC}^{\text {high }}$ cells by this way to apoptosis (11). In line with our data that double treatment with quercetin and sulforaphane is most effective, Castillo-Pichardo et al (26) demonstrated that combined dietary grape polyphenols 
resveratrol, quercetin, or catechin inhibited bone and liver metastasis of breast cancer cells in mice much more efficiently in combination than each single agent alone. This was due to induction of apoptosis and downregulation of NF$\kappa \mathrm{B}$ activity. In the present study quercetin increased NF- $\mathrm{NB}$ DNA-binding of transactivation active p65/cRel complexes. This feature of quercetin was unexpected, since it suggests survival signaling and induction of apoptosis resistance. However, NF-кB has many functions in the cell and the resulting signaling depends on the cellular context. Therefore, it may be speculated that mixed plant substances complement each other and have functions necessary for both survival of normal cells and suicide of malignant cells. Differential interference of quercetin and sulforaphane with cellular pathways may protect normal cells but eliminate highly malignant CSCs. This assumption is reinforced by our experiments in which we observed minimal toxicity in primary human fibroblasts and mesenchymal stromal/stem cells upon incubation with quercetin and sulforaphane (11). Our data are consistent with the findings of Orzechowski et al (27) who demonstrated quercetin-induced enhanced binding of p65/cRel containing $\mathrm{NF}-\kappa \mathrm{B}$ dimers in nuclear extracts of murine lymphocytic leukemia cells. Conversely, other authors show inhibition of NF- $\mathrm{KB}$ binding activity in response to quercetin $(19,28)$. These differences in the quercetin-induced effect to $\mathrm{NF}-\mathrm{\kappa B}$ may be best explained by the use of different cancer models.

Another factor associated with metastatic features is angiogenesis. Our xenograft studies reflect a significant inhibition of blood vessel density induced by quercetin, in line with recent data showing inhibition of in vitro tube formation by quercetin above $100 \mu \mathrm{M}$ (29). Anti-angiogenic effects of sulforaphane have also been reported using a model of primary human endothelial cells (30). However, in our xenograft model sulforaphane did not significantly alter vessel formation, probably due to very weak effects in vivo. Recently, strong angiogenic effects of the quercetin-related isoflavonoid genistein, present in high concentration in soybeans, have been demonstrated (31). Genistein downregulated angiogenesis in pancreatic tumor xenografts by inhibition of hypoxia-inducible factor-1 and its target gene VEGF (31). This mechanism may be responsible for the observed genistein-mediated prevention of metastasis in mice orthotopically transplanted with the CSC $^{\text {high }}$ MIA-PaCa2 cells (32).

Involvement of EMT in prevention of metastasis by genistein is likely, but was not examined in the studies by Büchler et al cited above. However, our data obtained with quercetin point to this direction. The expression pattern of proteins involved in EMT in our experiments is in line with a recent study showing that sensitive pancreatic cancer cells express E-cadherin but not vimentin, while the resistant cell lines miss expression of E-cadherin (33). This finding is interesting, since there is a notion that CSCs may actually not be distinct entities, but rather tumor cells that transiently acquire stem cell-like properties as a consequence of EMT processes (34). The correlation between CSCs and EMT suggests that the stem cells of certain epithelial organs show many of the attributes of the mesenchymal cell state (35). Creighton et al have shown that the residual breast tumor cell populations surviving after conventional treatment may be enriched for subpopulations of cells with both tumor-initiating and mesenchymal features (36). Vesuna et al demonstrated that the overexpression of Twist in breast cells can promote the generation of a breast cancer stem cell phenotype characterized by the high expression of CD44, little or no expression of CD24, and increased ALDH1 activity (22). In addition, Twist-overexpressing cells exhibit high efflux of Hoechst 33342 and Rhodamine 123 as a result of increased expression of ABCC1 (MRP1) transporters, which is another suggested property of CSCs (37). The selection of CSCs by Twist overexpression is suggested to be due to a Twistmediated transcriptional up-regulation of the CSC marker CD24 (22). In the present study, quercetin alone and even stronger in combination with sulforaphane downregulated expression of Twist2, suggesting inhibition of EMT.

Our findings show that neither quercetin nor sulforaphane exhibit pronounced toxicity to human primary mesenchymal stromal/stem cells or skin fibroblasts using concentrations toxic to pancreatic CSCs. Furthermore, no adverse side-effects were observed by treatment of mice transplanted with human pancreatic CSC xenografts. We found no loss of body weight, or necrotic liver areas. Also, the mice looked healthy during the treatment. These findings suggest that quercetin in combination with sulforaphane is likely to be safe as a therapeutic modality. Our results are in line with studies of the half lethal dose $\left(\mathrm{LD}_{50}\right)$ of quercetin in mice, which is with $159 \mathrm{mg} / \mathrm{kg}$ thrice as high than the concentration of $50 \mathrm{mg} / \mathrm{kg}$ used in our studies (38). The tolerance of quercetin is further supported by the results of a phase I study showing that quercetin is well tolerated by patients with advanced liver and ovarian cancers (39). In this study, i.v. infusion of 1400 $\mathrm{mg} / \mathrm{m}^{2}(35 \mathrm{mg} / \mathrm{kg})$ quercetin was recommended. In 9 of 11 patients, lymphocyte protein tyrosine phosphorylation was inhibited following administration of quercetin at $1 \mathrm{~h}$, which persisted to $16 \mathrm{~h}$. In one patient with ovarian cancer refractory to cisplatin, following two courses of quercetin $\left(420 \mathrm{mg} / \mathrm{m}^{2}\right)$, the CA 125 had fallen from 295 to $55 \mathrm{U} / \mathrm{ml}$, and in another patient with hepatoma, the serum $\alpha$-fetoprotein decreased. These data are underlined by the results of a multiethnic cohort study, which demonstrates that a diet containing flavonoids reduces the risk of pancreatic cancer (40). In spite of this promising clinical data, the therapeutic active doses of quercetin are hard to achieve by nutrition only. Estimated doses of quercetin that will be reached after the consumption of $11 \mathrm{red}$ wine, $1 \mathrm{~kg}$ apples, $1 \mathrm{~kg}$ yellow onions or $1 \mathrm{~kg}$ broccoli are 19, 140, 347 or $30 \mathrm{mg}$, respectively (41-43). Better sources for therapeutic active concentrations of quercetin are commercially available dietary supplements with a typical concentration of $500 \mathrm{mg}$ bioavailable quercetin per tablet.

Epidemiological evidence from a Canadian prospective study of fruit and vegetable intake suggests that high intake of broccoli and cauliflower is associated with a reduced risk of aggressive prostate cancer (44). These data indicate that sulforaphane, the major bioactive ingredient of these vegetables, may be involved in preventing metastasis by targeting of prostate CSCs. However, as stated above for quercetin, therapeutic levels of sulforaphane are hard to achieve by nutrition alone. For example, one serving of $100 \mathrm{~g}$ standard broccoli contains about $11 \mathrm{mg}$ of the sulforaphane precursor 
glucoraphanin $(45,46)$. A much higher sulforaphane concentration can be obtained by intake of broccoli sprouts, which contain 20-100 times more glucoraphanin than full-grown broccoli (47). The intake of dietary supplements produced from broccoli sprout extracts are available at concentrations of $30 \mathrm{mg}$ glucoraphanin per tablet. Nevertheless, as suggested by the data of the present study and by findings of others $(14,15,26)$ dietary agents act best in concert. Thus, upon intake of isolated dietary supplements the beneficial effects may be much weaker and more unspecific than with a natural occuring mixure of bioactive plant ingredients.

In conclusion, we demonstrate for the first time that quercetin targets pancreatic CSC features, which can be enforced by co-incubation with sulforaphane. Underlying molecular mechanisms affect self-renewal potential, ALDH1 activity, apoptosis induction, inhibition of angiogenesis, $\mathrm{NF}-\kappa \mathrm{B}$ and EMT processes in vitro and in mice. Since we did not observe any toxic side-effects, combination of quercetin and sulforaphane may be save for cancer prevention and treatment in the clinical setting.

\section{Acknowledgements}

We thank Dr P. Altevogt for mouse mAb CD24 from SWA-11 hybridoma and Dr H.-J. Stark for primary skin fibroblasts. This study was supported by grants from the Bundesministerium für Bildung und Forschung (01GU0611), Tumorzentrum Heidelberg/Mannheim [D10027(6)350], Stiftung Chirurgie Heidelberg, Dietmar-Hopp Stiftung, Deutsche Krebshilfe (107254), Deutsche Forschungsgemeinschaft (SFB 518/A17). W.Z. is a research fellow of the China Scholarship Council.

\section{References}

1. Reya T, Morrison SJ, Clarke MF and Weissman IL: Stem cells, cancer, and cancer stem cells. Nature 414: 105-111, 2001.

2. Dontu G, Abdallah WM, Foley JM, et al: In vitro propagation and transcriptional profiling of human mammary stem/progenitor cells. Genes Dev 17: 1253-1270, 2003.

3. Ribacka C, Pesonen S and Hemminki A: Cancer, stem cells, and oncolytic viruses. Ann Med 40: 496-505, 2008.

4. Lim E, Vaillant F, Wu D, et al: Aberrant luminal progenitors as the candidate target population for basal tumor development in BRCA1 mutation carriers. Nat Med 15: 907-913, 2009.

5. Li C, Heidt DG, Dalerba P, et al: Identification of pancreatic cancer stem cells. Cancer Res 67: 1030-1037, 2007.

6. Hermann PC, Huber SL, Herrler T, et al: Distinct populations of cancer stem cells determine tumor growth and metastatic activity in human pancreatic cancer. Cell Stem Cell 1: 313323, 2007

7. Arlt A, Vorndamm J, Breitenbroich M, et al: Inhibition of NF-kappaB sensitizes human pancreatic carcinoma cells to apoptosis induced by etoposide (VP16) or doxorubicin. Oncogene 20: 859-868, 2001

8. Pan X, Arumugam T, Yamamoto T, et al: Nuclear factor-kappaB p65/RelA silencing induces apoptosis and increases gemcitabine effectiveness in a subset of pancreatic cancer cells. Clin Cancer Res 14: 8143-8151, 2008.

9. Huber MA, Azoitei N, Baumann B, et al: NF-kappaB is essential for epithelial-mesenchymal transition and metastasis in a model of breast cancer progression. J Clin Invest 114: 569$581,2004$.

10. Heiss E, Herhaus C, Klimo K, Bartsch H and Gerhauser C: Nuclear factor kappa B is a molecular target for sulforaphanemediated anti-inflammatory mechanisms. J Biol Chem 276: 32008-32015, 2001

11. Kallifatidis G, Rausch V, Baumann B, et al: Sulforaphane targets pancreatic tumour-initiating cells by NF-kappaB-induced antiapoptotic signalling. Gut 58: 949-963, 2009.
12. Shishodia S, Amin HM, Lai R and Aggarwal BB: Curcumin (diferuloylmethane) inhibits constitutive NF-kappaB activation, induces $\mathrm{G} 1 / \mathrm{S}$ arrest, suppresses proliferation, and induces apoptosis in mantle cell lymphoma. Biochem Pharmacol 70: 700-713, 2005 .

13. Pradeep CR and Kuttan G: Piperine is a potent inhibitor of nuclear factor-kappaB (NF-kappaB), c-Fos, CREB, ATF-2 and proinflammatory cytokine gene expression in B16F-10 melanoma cells. Int Immunopharmacol 4: 1795-1803, 2004.

14. Kakarala M, Brenner DE, Korkaya $\mathrm{H}$, et al: Targeting breast stem cells with the cancer preventive compounds curcumin and piperine. Breast Cancer Res Treat (In press).

15. Pappa G, Strathmann J, Lowinger M, Bartsch H and Gerhauser C: Quantitative combination effects between sulforaphane and 3,3'-diindolylmethane on proliferation of human colon cancer cells in vitro. Carcinogenesis 28: 1471-1477, 2007.

16. Williamson G and Manach C: Bioavailability and bioefficacy of polyphenols in humans. II. Review of 93 intervention studies. Am J Clin Nutr 81: 243S-255S, 2005.

17. Beckermann BM, Kallifatidis G, Groth A, et al: VEGF expression by mesenchymal stem cells contributes to angiogenesis in pancreatic carcinoma. Br J Cancer 99: 622-631, 2008.

18. Koziol JA, Maxwell DA, Fukushima M, Colmerauer ME and Pilch YH: A distribution-free test for tumor growth curve analyses with application to an animal tumor immunotherapy experiment. Biometrics 37: 383-390, 1981.

19. Mouria M, Gukovskaya AS, Jung Y, et al: Food-derived polyphenols inhibit pancreatic cancer growth through mitochondrial cytochrome $\mathrm{C}$ release and apoptosis. Int $\mathrm{J}$ Cancer 98: 761-769, 2002.

20. Mulholland PJ, Ferry DR, Anderson D, et al: Pre-clinical and clinical study of QC12, a water-soluble, pro-drug of quercetin. Ann Oncol 12: 245-248, 2001.

21. Ginestier C, Hur MH, Charafe-Jauffret E, et al: ALDH1 is a marker of normal and malignant human mammary stem cells and a predictor of poor clinical outcome. Cell Stem Cell 1: 555-567, 2007.

22. Vesuna F, Lisok A, Kimble B and Raman V: Twist modulates breast cancer stem cells by transcriptional regulation of CD24 expression. Neoplasia 11: 1318-1328, 2009.

23. Kalluri R and Weinberg RA: The basics of epithelialmesenchymal transition. J Clin Invest 119: 1420-1428, 2009.

24. Lowy AM, Knight J and Groden J: Restoration of E-cadherin/ beta-catenin expression in pancreatic cancer cells inhibits growth by induction of apoptosis. Surgery 132: 141-148, 2002.

25. Nakanishi $\mathrm{C}$ and Toi M: Nuclear factor-kappaB inhibitors as sensitizers to anticancer drugs. Nat Rev Cancer 5: 297-309, 2005.

26. Castillo-Pichardo L, Martinez-Montemayor MM, Martinez JE, Wall KM, Cubano LA and Dharmawardhane S: Inhibition of mammary tumor growth and metastases to bone and liver by dietary grape polyphenols. Clin Exp Metastasis 26: 505-516, 2009.

27. Orzechowski A, Grzelkowska K, Zimowska W, et al: Induction of apoptosis and NF-kappaB by quercetin in growing murine L1210 lymphocytic leukaemic cells potentiated by TNF-alpha. Reprod Nutr Dev 40: 441-465, 2000.

28. Musonda CA and Chipman JK: Quercetin inhibits hydrogen peroxide $\left(\mathrm{H}_{2} \mathrm{O}_{2}\right)$-induced NF-kappaB DNA binding activity and DNA damage in HepG2 cells. Carcinogenesis 19: 1583-1589, 1998.

29. Igura K, Ohta T, Kuroda Y and Kaji K: Resveratrol and quercetin inhibit angiogenesis in vitro. Cancer Lett 171: 11-16, 2001.

30. Bertl E, Bartsch H and Gerhauser C: Inhibition of angiogenesis and endothelial cell functions are novel sulforaphane-mediated mechanisms in chemoprevention. Mol Cancer Ther 5: 575-585, 2006.

31. Büchler P, Reber HA, Büchler MW, Friess H, Lavey RS and Hines OJ: Antiangiogenic activity of genistein in pancreatic carcinoma cells is mediated by the inhibition of hypoxiainducible factor- 1 and the down-regulation of VEGF gene expression. Cancer 100: 201-210, 2004.

32. Büchler P, Gukovskaya AS, Mouria M, et al: Prevention of metastatic pancreatic cancer growth in vivo by induction of apoptosis with genistein, a naturally occurring isoflavonoid. Pancreas 26: 264-273, 2003.

33. Arumugam T, Ramachandran V, Fournier KF, et al: Epithelial to mesenchymal transition contributes to drug resistance in pancreatic cancer. Cancer Res 69: 5820-5828, 2009. 
34. Thompson EW and Williams ED: EMT and MET in carcinoma clinical observations, regulatory pathways and new models. Clin Exp Metastasis 25: 591-592, 2008.

35. Mani SA, Guo W, Liao MJ, et al: The epithelial-mesenchymal transition generates cells with properties of stem cells. Cell 133: 704-715, 2008

36. Creighton CJ, Li X, Landis M, et al: Residual breast cancers after conventional therapy display mesenchymal as well as tumorinitiating features. Proc Natl Acad Sci USA 106: 13820-13825, 2009.

37. Olempska M, Eisenach PA, Ammerpohl O, Ungefroren H, Fandrich F and Kalthoff H: Detection of tumor stem cell markers in pancreatic carcinoma cell lines. Hepatobiliary Pancreat Dis Int 6: 92-97, 2007

38. Sullivan M, Follis RJ and Hilgartner M: Toxicology of podophyllin. Proc Soc Exp Biol Med 77: 269-272, 1951.

39. Ferry DR, Smith A, Malkhandi J, et al: Phase I clinical trial of the flavonoid quercetin: pharmacokinetics and evidence for in vivo tyrosine kinase inhibition. Clin Cancer Res 2: 659-668, 1996.

40. Nothlings U, Murphy SP, Wilkens LR, et al: A food pattern that is predictive of flavonol intake and risk of pancreatic cancer. Am J Clin Nutr 88: 1653-1662, 2008.

41. De Vries JH, Hollman PC, van Amersfoort I, Olthof MR and Katan MB: Red wine is a poor source of bioavailable flavonols in men. J Nutr 131: 745-748, 2001
42. Hertog MGL, Hollman PCH and Katan MB: Content of potentially anticarcinogenic flavonoids in 28 vegetables and 9 fruits commonly consumed in The Netherlands. J Agric Food Chem 40: 2379-2383, 1992.

43. Herrmann K: Flavonols and flavones in food plants: a review. J Food Technol 11: 433-448, 1976.

44. Kirsh VA, Peters U, Mayne ST, et al: Prospective study of fruit and vegetable intake and risk of prostate cancer. J Natl Cancer Inst 99: 1200-1209, 2007.

45. Gasper AV, Traka M, Bacon JR, et al: Consuming broccoli does not induce genes associated with xenobiotic metabolism and cell cycle control in human gastric mucosa. J Nutr 137: 1718-1724, 2007.

46. Traka M, Gasper AV, Melchini A, et al: Broccoli consumption interacts with GSTM1 to perturb oncogenic signalling pathways in the prostate. PLoS One 3: e2568, 2008.

47. Fahey JW, Zhang Y and Talalay P: Broccoli sprouts: an exceptionally rich source of inducers of enzymes that protect against chemical carcinogens. Proc Natl Acad Sci USA 94: 10367-10372, 1997. 